\title{
Penetrating Abdominal Injuries: Pattern and Outcome of Management in Khartoum
}

\author{
Maha Yassin Omer ${ }^{1}$, Aamir Abdullahi Hamza ${ }^{2 *}$, Mohammed Toum Musa ${ }^{3}$ \\ ${ }^{1}$ Department of Surgery, Faculty of Medicine, Al Neelain University, Khartoum, Sudan; ${ }^{2}$ Department of Surgery, College of Medi- \\ cine \& Health Sciences, Bahri University, Khartoum, Sudan; ${ }^{3}$ Department of Surgery, Faculty of Medicine, Khartoum University, \\ Khartoum, Sudan. \\ Email: aamirhamzza@yahoo.co.uk
}

Received October $26^{\text {th }}, 2013$; revised November $22^{\text {nd }}, 2013$; accepted December $20^{\text {th }}, 2013$

Copyright (C) 2014 Maha Yassin Omer et al. This is an open access article distributed under the Creative Commons Attribution License, which permits unrestricted use, distribution, and reproduction in any medium, provided the original work is properly cited. In accordance of the Creative Commons Attribution License all Copyrights @ 2014 are reserved for SCIRP and the owner of the intellectual property Maha Yassin Omer et al. All Copyright (C) 2014 are guarded by law and by SCIRP as a guardian.

\section{ABSTRACT}

Background: The pattern and presentation of penetrating abdominal trauma vary according to places and the structure of the present health system. As well controversies in management exist ranging from mandatory exploration to selective non-operative management. Objectives: To determine the pattern of penetrating abdominal trauma, current management practiced and outcome in Khartoum. Patients and Methods: The study was prospective, descriptive and hospital-based. It was carried out at the main three hospitals in Khartoum State. It was conducted over a period of one year from 2012 Mar to 2013 Mar. All patients who presented penetrating injury to their abdomen were included. Results: The study included 85 patients with a mean age of 28 years (SD \pm 10$)$. The male to female ratio was 11:1. Most of the patients $(\mathbf{8 9 . 4 \% )}$ were in the first four decades of their life. Twenty-three patients $(27.1 \%)$ presented shock. Stab wound is the commonest mode of trauma seen in $83.5 \%$ of our patients. The majority of our patients were managed by exploratory laparotomy (81.2\%), however 16 $(\mathbf{1 8 . 8} \%)$ underwent conservative measures. Of the operated group, solid organ injuries were found in $22.9 \%$, yet hollow viscous injuries were reported in $86.9 \%$ of the patients. Registrars operated on $78.26 \%$ of the patients. The rate of negative laparotomy of this study was $8.7 \%$. Complications and mortality were encountered in $25.9 \%$ and $4.7 \%$ respectively. The mean hospital stay was 8.47 days $(S D \pm 10.6)$. Conclusion: This study demonstrates no difference in the pattern of intra-abdominal injuries. The rate of operative treatment is acceptable, but more laparotomies can be avoided if the haemodynamic stable patients without features of peritonitis were given a period of observation. The overall outcome was satisfactory.

\section{KEYWORDS}

\section{Mandatory Laparotomy; Mortality; Non-Operative Management; Penetrating Abdominal Injuries}

\section{Introduction}

Trauma is still the most frequent cause of death in the first four decades of life, and it remains a major public health problem in every country, regardless of the level of socioeconomic development [1]. The policy of mandatory exploration of penetrating abdominal wounds, particularly gunshot wounds (GSWs), remained largely unchallenged until the 1990s, when civilian authors reported the successful use of selective non-operative man-

\footnotetext{
${ }^{*}$ Corresponding author.
}

agement of abdominal GSWs [2]. The abdominal viscera are among the most vulnerable organs of the body to penetrating trauma. The small intestine and colon respectively were the most prevalent abdominal organs damaged [3].

\section{Patients and Methods}

The study is a prospective, descriptive and analytic. It was carried out at the main three hospitals in Khartoum state, namely "Khartoum Teaching Hospital-KTH, Khartoum North Teaching Hospital-KNTH and Omdurman Teaching Hospital—OTH”. It was conducted 
over a period of one year from 2012 Mar to 2013 Mar. All patients who presented with penetrating injury to their abdomen were included in the study. Patients presented with blunt abdominal trauma or penetrating trauma other than the abdomen were excluded. Nonprobability sampling technique was used; Data were collected using a predesigned and pretested questionnaire. The variables includes personal data, mode of trauma, presenting symptoms, findings on examination, intervention, operative findings and the outcome of management. Data were analyzed using Statistical Package for Social Sciences (SPSS) version 20, and the P-value was considered significant if $<0.05$. Consent was obtained from all patients prior to participation into the study, together with the ethical clearance.

\section{Results}

This study included 85 patients. Their mean age was 28 years ( $S D \pm 10)$, ranging from 2 to 65 years. Penetrating abdominal injuries (PAIs) were common in the first four decade of life 76 (89.4\%). The age group 21 - 40 years was the most involved representing 55 (64.7\%) (Table 1). Males were predominant 78 (91.8\%) whereas females were only 7 (8.2\%) making a male to female ratio of 11:1. The patients presented and managed at KTH were 44 (51.8\%), OTH 27 (31.8\%) and KNTH 14 (16.5\%). Twenty three patients $27.1 \%$ presented to the accident and emergency department in state of shock and 20 (23.5\%) with features of peritonitis. The mode of trauma varies between stab with knives or other sharp structures in $71(83.5 \%)$ and gunshot wounds in $14(16.5 \%)$. According to the site of the stab; the majority of our patients $62(72.9 \%)$ sustained the trauma in their anterior abdomen, $10(11.8 \%)$ in the flanks, 7 (8.2\%) in the thoracoabdominal, 4 (4.7\%) posterior abdomen and two patients (2.4\%) had multiple stabs involving the posterior abdomen and the flank.

Evisceration through the stab wound was noted in 30 (35.3\%) of the patients. The majority of them were omentum alone in $10(33.8 \%)$ or associated with bowel in $4(13.3 \%)$, followed by the small bowel alone in 7 $(23.3 \%)$ or associated with either omentum, stomach or

Table 1. Age and gender distribution in the study population $(\mathbf{n}=\mathbf{8 5})$.

\begin{tabular}{|c|c|c|c|}
\hline \multirow{2}{*}{ Age (years) } & \multicolumn{2}{|c|}{ Gender } & \multirow{2}{*}{ Total } \\
\hline & Male & Female & \\
\hline$\leq 20$ & 18 & 03 & $21(24.7 \%)$ \\
\hline $21-40$ & 51 & 04 & 55 (64.7\%) \\
\hline $41-60$ & 08 & 00 & 08 (09.4\%) \\
\hline$\geq 61$ & 01 & 0 & 01 (01.2\%) \\
\hline Total & 78 (91.8\%) & 07 (08.2\%) & 85 (100\%) \\
\hline
\end{tabular}

the colon, in 8 (26.7\%) of the patients.

Imaging was done to 17 (20\%) of the patients. Of them (58.8\%) were focused abdominal sonographies in trauma (FAST), 5 (29.4\%) plain abdominal and chest radiographies whereas CT scans were only done to two patients (11.8\%). Local exploration of the wound was done to 28 (32.9\%), in 18 of them (64.3\%) it was involving the peritoneum and negative in 10 patients (35.7\%). In 67.1\% of the study group local wound exploration was not attempted. The operators were registrars, surgeons and medical officers, constituting 54 (78.26\%), 14 (20.29\%) and one $(1.45 \%)$ respectively. The mean operative time was 2.6 hours $(\mathrm{SD} \pm 0.84)$. However it was $1-2$ hours in $40(57.97 \%)$ of the patients, more than two hours in 25 (36.23\%) and took less than an hour in only four patients. All our patients received prophylactic injectable antibiotics, 60 (70.6\%) of them were Cefuroxime and Metronidazole infusion, 15 (17.7\%) had Metronidazole with Cefatazidime and the rest Cephalosporin alone. However the majority $56(81.16 \%)$ were contaminated and 13 (18.84\%) were dirty wounds and antibiotic was continued as treatment.

\subsection{Intra-Operative Findings and Procedures Performed}

The majority of our patients were managed by exploratory laparotomy 69 (81.2\%) however 16 (18.8\%) underwent conservative measures. Different combinations of abdominal organs were seen intra-operatively in many patients 26 (37.7\%). However Table 2 shows the frequency of individual organ damage in the study disregarding these combinations. Hollow viscus injuries (stomach, small and large bowel) occurred in $86.9 \%$, while solid organ injuries (liver, spleen and kidneys) in 22.9\%. All stomach, diaphragmatic, vascular, ureteric and isolated anterior abdominal injuries were repaired. Small bowel injuries were seen in 27 (39.1\%), two third of them 19 (27.5\%) ended with resection and anastomosis due to multiple injuries. While in large bowel trauma 23 (33.3\%), colostomies were fashioned to the majority of them (16 (23.2\%)). Splenic injuries were reported in 10 $(14.5 \%)$ and splenectomy was carried out in 8 (11.6\%). Renal injuries were seen in 6 (8.7\%), and one patient had nephrectomy.

\subsection{Outcome}

Most of the patients 59 (69.4\%) run smooth post-operative course and discharged home in good general condition. Complications were encountered in 22 (25.9\%) and four patients died. The causes of their death were (haemorrhagic shock, sepsis and pulmonary embolus). Surgical site infection was seen in $16.4 \%$ from the whole study group. It constituted $63.4 \%$ from the group who developed complications, entero-cutaneous fistula in 
Table 2. Subtype of abdominal injuries (many combinations were seen) and their treatment in the operated patients $(n=$ 69).

\begin{tabular}{cccc}
\hline Injured organ & $\begin{array}{c}\text { No } \\
\text { (Percent) }\end{array}$ & Procedure done & $\begin{array}{c}\text { No } \\
\text { (Percent) }\end{array}$ \\
\hline Stomach & $10(14.5 \%)$ & Stomach repair & $10(14.5 \%)$ \\
Small Bowel & $27(39.1 \%)$ & R \& A $^{\mathrm{a}}$ & $19(27.5 \%)$ \\
Large Bowel & $23(33.3 \%)$ & SB $^{\mathrm{b}}$ Repair & $08(11.6 \%)$ \\
Liver & $06(08.7 \%)$ & Copair of LB & $07(10.1 \%)$ \\
Spleen & $10(14.5 \%)$ & Splomy & $16(23.2 \%)$ \\
& & Splenorrhaphy & $02(02.9 \%)$ \\
Kidney & $06(08.7 \%)$ & Kidney repair & $05(07.2 \%)$ \\
& & Nephrectomy & $01(01.4 \%)$ \\
Diaphragm & $06(08.7 \%)$ & Diaphragm repair & $06(08.7 \%)$ \\
Vascular & $05(07.2 \%)$ & Vascular repair & $05(07.2 \%)$ \\
Ureter & $01(01.4 \%)$ & Ureteric repair & $01(01.4 \%)$ \\
AAW & $10(14.5 \%)$ & AAW ${ }^{\mathrm{d}}$ repair & $10(14.5 \%)$ \\
\hline
\end{tabular}

${ }^{\mathrm{a}}$ Resection \& anastomosis; ${ }^{\mathrm{b}}$ Small bowel; ${ }^{\mathrm{c}}$ Large bowel; ${ }^{\mathrm{d}}$ Anterior abdominal wall.

$13.64 \%$ and venous-thromboembolism in one patient, (Table 3). The mean hospital stay was 8.5 days (SD \pm 10.6).

\section{Discussion}

Penetrating abdominal injuries (PAIs) in Africa constituted $30 \%-66 \%$ of the overall abdominal trauma burden in the accident and emergency department [4-7]. In our study it affects young patients, where the mean age was found to be 28 years. This is comparing to a mean age of 28 to 30 years, reported in other studies $[7,8,10-13]$. The great majority of our patients (89.4\%) were in the first four decades of their life. This had been described by another author previously [8]. The preponderance of male gender $91.9 \%$ in our study was well described by others, $82.2 \%$ - 96.5\% [5,8,9,11-14] and this might be explained by the fact that males were the bread earners.

\subsection{Mode of Trauma, Injury Pattern}

The causes of PAIs vary from place to place. In Sudan stab with knives or other sharp objects, ranked first as evident from this study $83.5 \%$ and a rate of $88.5 \%$ had been reported previously in Khartoum [4]. PAI was the mode of trauma in less than half of the patients in other studies [7,8,10], however in further series it was over $60 \%$ $[6,9,13]$. Gunshot injuries was documented in $16.5 \%$ in this study which was equivalent to others $[4,8,14]$, how-
Table 3. Types of complications in patients with penetrating abdominal injuries $(n=22)$.

\begin{tabular}{ccc}
\hline Complication & Frequency & Percent \\
\hline Surgical site infection & 14 & 63.64 \\
Wound dehiscence & 01 & 04.55 \\
Abdominal abscess & 02 & 09.09 \\
Entero-cutaneous fistula & 03 & 13.64 \\
Leak of large bowel & 01 & 04.55 \\
VTE $^{\text {a }}$ & 01 & 04.55 \\
Total & 22 & 100.0 \\
\hline
\end{tabular}

${ }^{\mathrm{a}}$ Venous thrombo-embolism.

ever different authors in the literature revised, reported different magnitude of 23.0\% [15], 29.4\% [9], 31.1\% [6], $38.0 \%$ [7], 49.2\% [8] and 79.8\% [10]. This reflects the combination of the associated intra-abdominal injured organs that frequently encountered in gunshot abdominal trauma.

\subsection{Presentation}

The presentation of patients with PAI might be in state of haemorrhagic shock, features of peritonitis or just with omentum/bowel evisceration. In our study $27.1 \%$ were haemodynamically unstable when first seen and this agrees with 28\% [4], but contrast with $11 \%$ in Munguni, et al. [8] and 17.9\% in Monzon, et al. [10] studies. In these cases of shock solid organ injuries were commonly the reason. However peritonitis came next with incidence of $23.5 \%$ in our series, which was comparable to others $[4,10]$. In this respect hollow organ injuries were frequently encountered.

\subsection{Site of the PAI}

The anterior abdomen was the site commonly wounded, with $72.9 \%$ in our study and similarly described by A Salim et al., 65\% [11] but to lesser extend 34.8\% in Monzon et al., study [10]. Thoraco-abdsominal, which is superiorly delimited by the fourth intercostal space (anterior), sixth intercostal space (lateral), and eighth intercostal space (posterior), and inferiorly delimited by the costal margin [2] seen in $8.2 \%$ of the sample we studied, but this is a bit lower than reported $20.5 \%$ by A Salim et al., [11]. Although PAIs from the back region was found in only four patients $4.7 \%$, it was considered lower to other $14.5 \%$ [11]. In four of our patients $4.7 \%$ their surgery was limited only to wound exploration as there was no evidence of peritoneal penetration and this compares well to other studies [13].

\subsection{Treatment}

Non-operative management of blunt abdominal solid 
organ injuries has become the standard of care [16]. However, routine surgical exploration remains the standard practice for all penetrating solid organ injuries. Although there is no debate that patients with peritonitis or haemodynamic instability should undergo urgent laparotomy after penetrating injury to the abdomen, it is also clear that certain stable patients without peritonitis may be managed without operation [17]. The rate of nonoperative management in our study was $18.1 \%$ and this in agreement with $10.1 \%$ [10], 13.8\% [7] and 15.3\% [4]. However, in one study almost quarter of the patients with PAI were managed conservatively, yet A Salim on his study when to operate on gunshot he managed to discharged 79\% from the hospital without surgery [11]. The rate of operative management of $81.2 \%$ in our study lie within the range reported in the literature $[4-8,10-13,18]$, Table 4.

\subsection{Intra-Abdominal Injuries}

The most common traumatized abdominal organ in our study, was the bowel 72.5\% (large 33.3\%, small 39.1\%), followed by stomach and spleen each in ten patients $14.5 \%$. In the literature small bowel injuries accounted for $23 \%-74 \%[4,7,10,13,19,20]$, while large bowel reported in $6.3 \%$ - 33.7\% [7,9,10,13,20]. It seems clearly that our small bowel and large bowel injuries go well with other's works. The described stomach injuries $0.0 \%$ - 23.6\% $[4,7,10,13,20]$ and diaphragmatic injuries $0.0 \%$ $9 \%[9,10,13]$, were nearly similar to ours.

In $31.9 \%$ of our patients solid organs trauma was faced (liver $8.7 \%$, spleen $14.4 \%$, kidneys $8.7 \%$ ). On revising other studies, the rate of our liver injuries was found to be similar to $7 \%$ [9] and $10 \%$ [13], whereas it was noti-

Table 4. The percentage of operative treatment in patients with penetrating abdominal injuries among different studies.

\begin{tabular}{ccc}
\hline Study & Year & OPM $^{\mathrm{a}}$ \\
\hline Salim A, et al. [11] & 2002 & $21 \%$ \\
Monzon BI, et al. [10] & 2004 & $89.9 \%$ \\
Musau PE, et al. [6] & 2006 & $75.5 \%$ \\
Pradeep H, et al. [12] & 2007 & $42.2 \%$ \\
Alec C, et al. (16) [18] & 2008 & $41.4 \%$ \\
Siddig HD, et al. [4] & 2008 & $69.4 \%$ \\
Ohene M, et al. [13] & 2010 & $85.5 \%$ \\
Maurice, et al. [7] & 2012 & $86.2 \%$ \\
Mohammad A, et al. [5] & 2012 & $28.3 \%$ \\
Mnguni MN, et al. [8] & 2012 & $90 \%$ \\
Current study & 2013 & $81.2 \%$ \\
\hline
\end{tabular}

${ }^{\mathrm{b}}$ Operative management. ceably contrasting $13.8 \%$ [4], $14.6 \%$ [10], 26.7\% [20] and $33.3 \%$ [21]. However splenic injuries in the literature were similar to ours $[7,10,13]$. No biliary, pancreatic or duodenal injuries were reported in our series as others [7, 22]. Six of our patients (8.7\%) were found intra-operatively to have left diaphragmatic injury, following PAI to the thorac-abdominal region. This simulates other findings, where the injury occurs on the left in $66 \%[10,23]$. The difficulty is that diaphragmatic injuries, particularly after penetrating trauma, may initially go unnoticed, and without changes in the CXR images, diagnosis is made difficult, so high index of suspension is required [24]. Our rate of negative laparotomy compares well with Maurice et al. (4\%) [7] and Pradeep et al. 8.1\% [12], while M Ohene et al. [13] found up to $29.0 \%$ of his patients with no significant detected intra-abdominal injury at laparotomy.

\subsection{Outcome}

Patients who recovered satisfactory without complications in our study $69.4 \%$ compares well with Maurice et al., 84\% [7] and Monzon et al., 69.6\% [10]. The rate of post-operative morbidity was high in our patients compared to $6 \%-8 \%$ in other series $[4,8]$. This was attributed to the development of surgical site infection, though our frequency of $16.4 \%$ was comparable to $6.9 \%$ - $18 \%$ level of wound infection documented by others [7, 11]. In our study there were four mortal cases $4.7 \%$ and this is similar to the findings in the literature $[3,4,6-8,10$, 13]. The duration of admission in this study was 8.5 days, in keeping with previous studies elsewhere that confirmed the mean time for hospitalization to range between 9.2 and 10.5 days [6-8].

\section{Conclusion}

In conclusion, this study demonstrates no difference in the pattern of intra-abdominal injuries regardless of the mode of penetrating abdominal trauma. The rate of operative treatment is acceptable, but more laparotomies can be avoided if the haemodynamic stable patients without features of peritonitis were given a period of observation. The overall outcome was satisfactory.

\section{REFERENCES}

[1] M. Aldemir, I. Tacyildiz and S. Girgin, "Predicting Factors for Mortality in the Penetrating Abdominal Trauma," Acta Chirurgica Belgica, Vol. 104, No. 4, 2004, pp. 429434.

[2] D. Demetriades and G. Velmahos, “Technology-Driven Triage of Abdominal Trauma: The Emerging Era of Nonoperative Management," Annual Review of Medicine, Vol. 54, 2003, pp. 1-15.

http://dx.doi.org/10.1146/annurev.med.54.101601.152512 
[3] M. Saghafinia, N. Nafissi, M. R. Motamedi, M. H. Motamedi, M. Hashemzade, Z. Hayati and F. Panahi, “Assessment and Outcome of 496 Penetrating Gastrointestinal Warfare Injuries,” Journal of Royal Army Medical Corps, Vol. 156, No. 1, 2010, pp. 25-27. http://dx.doi.org/10.1136/jramc-156-01-05

[4] H. D. Siddig and M. E. Ahmed, "Management of Abdominal Trauma in Khartoum Teaching Hospital," Khartoum Medical Journal, Vol. 1, No. 3, 2008, pp. 112-115.

[5] M. A. Gad, Aly Saber, Shereif Farrag, M. E. Shams and G. M. Ellabban, "Incidence, Patterns, and Factors Predicting Mortality of Abdominal Injuries in Trauma Patients,” North American Journal of Medical Sciences, Vol. 4, No. 3, 2012, pp. 129-134. http://dx.doi.org/10.4103/1947-2714.93889

[6] P. Musau, P. G. Jani and F. A. Owillah, "Pattern and Outcome of Abdominal Injuries at Kenyatta National Hospital," Nairobi, East African Medical Journal, Vol. 83, No. 1, 2006, pp. 37-42. http://dx.doi.org/10.4314/eamj.v83i1.9359

[7] M. Asuquo, M. Umoh, V. Nwagbara, G. Ugare, C. Agbor and E. Japhet, "Penetrating Abdominal Trauma: Experience in a Teaching Hospital, Calabar, Southern Nigeria," International Journal of Clinical Medicine, Vol. 3, No. 5, 2012, pp. 426-430. http://dx.doi.org/10.4236/ijcm.2012.35079

[8] M. N. Mnguni, D. J. J. Muckart and T. E. Madiba, “Abdominal Trauma in Durban, South Africa: Factors Influencing Outcome,” International Surgery, Vol. 97, No. 2, 2012, pp. 161-168. http://dx.doi.org/10.9738/CC84.1

[9] G. Ruhinda, P. Kyamanywa, D. Kitya and F. Bajunirwe, “Abdominal Injuries at Mbarara Regional Referral Hospital, Uganda,” East and Central Africa Journal of Surgery, Vol. 13, No. 2, 2008, pp. 29-36.

[10] B. I. Monzon-Torres and M. Ortega-Gonzalez, "Penetrating Abdominal Trauma,” SAJS, Vol. 42, No. 1, 2004, pp. 11-13.

[11] A. Salim and G. C. Velmahos, "When to Operate on Abdominal Gunshot Wounds," Scandinavian Journal of Surgery, Vol. 91, No. 1, 2002, pp. 62-66.

[12] H. P. Navsaria, J. U. Berli, S. Edu and A. J. Nicol, "Nonoperative Management of Abdominal Stab Wounds: An Analysis of 186 Patients,” SAJS, Vol. 45, No. 4, 2007, pp. 128-132.

[13] M. Ohene-Yeboah, J. C. B. Dakubo, F. Boakye1 and S. B. Naeeder, "Penetrating Abdominal Injuries in Adults Seen at Two Teaching Hospitals in Ghana,” Ghana Medical Journal, Vol. 44, No. 3, 2010, pp. 103-108.

[14] A. Gaudeuille, A. Doui Doumgba, J. Ndémanga Kamoune, E. Sacko and N. M. Nali, "Abdominal Trauma in Bangui (Central Africa): Epidemiologic and Anatomical Aspects,” Le Mali Médical, Vol. 22, No. 2, 2007, pp. 1922.
[15] J. G. Parreira, S. Rasslan and E. M. Utiyama, “Controversies in the Management of Asymptomatic Patients Sustaining Penetrating Thoracoabdominal Wounds," Clinics, Vol. 63, No. 5, 2008, pp. 695-700.

http://dx.doi.org/10.1590/S1807-59322008000500020

[16] D. Demetriades, P. Hadjizacharia, C. Constantinou, C. Brown, K. Inaba, P. Rhee and A. Salim, "Selective Nonoperative Management of Penetrating Abdominal Solid Organ Injuries,” Annals of Surgery, Vol. 244, No. 4, 2006, pp. 620-628.

[17] J. J. Como, F. Bokhari, W. C. Chiu, T. M. Duane, M. R. Holevar, M. A. Tandoh, R. R. Ivatury and T. M. Scalea, "Practice Management Guidelines for Selective Nonoperative Management of Penetrating Abdominal Trauma," Journal of Trauma, Vol. 68, No. 3, 2010 pp. 721-733.

[18] A. C. Beekley, L. H. Blackbourne, J. A. Sebesta, N. McMullin, P. S. Mullenix and C. J. B. Holcomb, "Selective Nonoperative Management of Penetrating Torso Injury from Combat Fragmentation Wounds,” The Journal of Trauma Injury, Infection, and Critical Care, Vol. 64, No. 2, pp. 108-117. http://dx.doi.org/10.1097/TA.0b013e31816093d0

[19] A. E. Dongo, E. B. Kesieme, D. O. Irabor and J. K. Ladipo, "A Review of Posttraumatic Bowel Injuries in Ibadan,” ISRN Surgery, Vol. 2011, 2011, Article ID: 478042. http://dx.doi.org/10.5402/2011/478042

[20] M. Uludag, G. Yetkn, B. Çitgez, F. Yener, I. Akgün and A. Çoban, "Effects of Additional Intraabdominal Organ Injuries in Patients with Penetrating Small Bowel Trauma on Morbidity and Mortality,” Turkish Journal of Traua \& Emergency Surgery, Vol. 15, No. 1, 2009, pp. 45-51.

[21] M. Bala, S. A. Gazalla, M. Faroja, A. I. Bloom, G. Zamir, A. I. Rivkind and G. Almogy, "Complications of High Grade Liver Injuries: Management and Outcomewith Focus on Bile Leaks," Scandinavian Journal of Trauma, Resuscitation and Emergency Medicine, Vol. 20, No. 20, 2012, pp. 1-7. http://dx.doi.org/10.1186/1757-7241-20-20

[22] S. Pandey, A. Niranjan, S. Mishra, T. Agrawal, B. M. Singhal, A. Prakash and P. C. Attri, "Retrospective Analysis of Duodenal Injuries: A Comprehensive Overview," The Saudi Journal of Gastroenterology, Vol. 17, No. 2, 2011, pp. 142-144. http://dx.doi.org/10.4103/1319-3767.77247

[23] A. P. Düzgün, M. M. Özmen, B. Saylam and F. Cofikun, "Factors Influencing Mortality in Traumatic Ruptures of Diaphragm,” Turkish Journal of Trauma \& Emergency Surgery, Vol. 14, No. 2, 2008, pp. 132-138.

[24] E. S. Hirano, V. G. Silva, J. B. Bortoto, R. H. de Oliveira Barros, N. M. G. Caserta and G. P. Fraga, "Plain Chest Radiographs for the Diagnosis of Post-Traumatic Diaphragmatic Hernia," Revista do Colégio Brasileiro de Cirurgiões, Vol. 39, No. 4, 2012, pp. 280-285. http://dx.doi.org/10.1590/S0100-69912012000400007 